\title{
Long-term (5- to 20-year) patency of the radial artery for coronary bypass grafting
}

\author{
Paul Achouh, MD, ${ }^{\mathrm{a}}$ Redha Boutekadjirt, MD, ${ }^{\mathrm{b}}$ Daniel Toledano, MD, ${ }^{\mathrm{b}}$ Nadjib Hammoudi, MD, ${ }^{\mathrm{c}}$ \\ Jean-Yves Pagny, MD, ${ }^{\mathrm{d}}$ Pascal Goube, MD, ${ }^{\mathrm{e}}$ Khaled Ould Isselmou, MD, ${ }^{\mathrm{a}}$ Bernard Lancelin, MD, \\ Régis Fouquet, $\mathrm{MD},{ }^{\mathrm{a}}$ and Christophe Acar, $\mathrm{MD}^{\mathrm{f}}$
}

Objective: The aim of this study was to assess the angiographic results of the radial artery as a coronary bypass conduit at long term ( $>5$ years).

Methods: Radial artery grafts were controlled in 202 patients at 10.1 years by conventional angiography $(\mathrm{n}=$ 79 ) and computed tomography $(n=123)$. Clinical or paraclinical evidence of ischemia was noted in 81 patients, whereas 121 patients were asymptomatic. Some 520 conduits were controlled: radial artery $(n=230)$, left internal thoracic artery $(n=190)$, right internal thoracic artery $(n=30)$, and veins $(n=70)$. Radial arteries were anastomosed to the right coronary $(24 \%)$, marginal $(58 \%)$, diagonal $(16 \%)$, and left anterior descending $(<1 \%)$ arteries, whereas left internal thoracic arteries were primarily anastomosed to the left anterior descending artery $(95 \%)$. The mean number of antithrombotic and anti-anginal medications was 1.2 and 1.9 per patient, respectively.

Results: The ejection fraction was slightly decreased compared with its preoperative value $(54 \% \pm 11 \%$ vs $57 \%$ $\pm 9 \% ; P=.009)$. Nine reoperations were required at 10.5 years for valve replacement $(\mathrm{n}=8)$ and isolated bypass $(\mathrm{n}=1)$. Percutaneous intervention was performed in 48 patients $(24 \%)$ at 7.6 years on a graft $(28 \%)$ or a native coronary artery $(72 \%)$. The 10 -year patency of radial artery grafts was $83 \%$, which was lower than the patency of left internal thoracic arteries $(95 \%, P<.001)$ and similar to the patency of right internal thoracic arteries $(87 \%, P$ $=.66)$ and veins $(81 \%, P=.50)$. No medication seemed to influence radial artery graft patency (aspirin: $P=.26$; calcium blockers: $P=.36$ ). All graft patency was lower when clinical or paraclinical evidence of ischemia was present than in asymptomatic cases $(83 \%$ vs $90 \% P=.02)$. The patency of left anterior descending grafts was higher than that of non-left anterior descending grafts $(96 \%$ vs $82 \% P<.001)$.

Conclusion: The radial artery-to-coronary bypass conduit provided a low coronary reoperation rate with an excellent patency (83\%) up to 20 years postoperatively. (J Thorac Cardiovasc Surg 2010;140:73-9)

Supplemental material is available online.

Introduced in the early 1970 s by Carpentier and colleagues, ${ }^{1}$ the use of the radial artery graft for coronary bypass grafting was initially flawed by a high failure rate and rapidly abandoned. Its use remained prohibited for approximately 2 decades. In 1989, favorable results led to its revival in

\footnotetext{
Department of Cardiovascular Surgery, ${ }^{\text {a }}$ Hôpital Georges Pompidou, Paris, France; Department of Radiology, ${ }^{\mathrm{b}}$ Hôpital Pitié Salpétrière, Paris, France; Department of Cardiology, ${ }^{\mathrm{c}}$ Hôpital Tenon, Paris, France; Department of Cardiology, ${ }^{\mathrm{d}}$ Clinique Labrouste, Paris, France; Department of Cardiology, ${ }^{\text {e }}$ Hôpital Sud-Francilien, Corbeil, France; and Department of Cardiac Surgery, ${ }^{\mathrm{f}}$ Hôpital Pitié-Saléptrière, Paris, France.

Disclosures: None.

Received for publication Feb 10, 2009; revisions received Aug 28, 2009; accepted for publication Sept 17, 2009; available ahead of print Nov 30, 2009.

Address for reprints: Christophe Acar, MD, Department of Cardiac Surgery, Heart Institute, Hôpital de la Salpétrière, 50-52 Bd Vincent Auriol, 75013 Paris, France (E-mail: c.acar@psl.aphp.fr).

0022-5223/\$36.00

Copyright (c) 2010 by The American Association for Thoracic Surgery doi:10.1016/j.jtcvs.2009.09.032
}

coronary surgery. ${ }^{2}$ The 1-year and 5-year clinical and angiographic results ${ }^{2,3}$ have been reported. The use of the radial artery is increasing, and it has been used routinely by several surgical centers for many years. Nevertheless, consistent data concerning its late patency are still missing. The aim of this study was to evaluate the long-term patency of radial artery grafts on control angiograms performed at more than 5 years and up to 20 years postoperatively.

\section{MATERIALS AND METHODS}

A total of 711 patients who survived coronary bypass grafting using the radial artery between July 1989 and December 2001 were recently reviewed. Only patients who had angiographic follow-up at more than 5 years were included. A total of 202 patients followed this criterion and constitute the study group. The end of the follow-up period was defined as the time of the most recent angiogram. Mean follow-up was $10.2 \pm$ 3.4 years and extended from 5.0 to 19.3 years.

\section{Patient Population}

At the end of follow-up, age was $69 \pm 9$ years and ranged from 41 to 89 years. Twelve patients had already undergone a previous surgical revascularization before radial artery grafting. In 19 patients, an additional procedure had been associated with coronary surgery: aortic $(n=4)$ or mitral $(n=1)$ valve replacement, mitral valve repair $(n=14)$, and atrial septal 


\author{
Abbreviation and Acronyms \\ $\mathrm{CT}=$ computed tomography \\ $\mathrm{ECG}=$ electrocardiogram \\ ITA $=$ internal thoracic artery \\ $\mathrm{LAD}=$ left anterior descending \\ PCI $=$ percutaneous coronary intervention
}

defect closure $(n=1)$. Table 1 shows the patient characteristics. Risk factors and extracardiac localization of atheroma were considered when either present at the time of surgery or noted during the follow-up period. Pharmacologic therapy, including antithrombotic treatment and vasodilators, prescribed at the time of the most recent angiographic control was recorded as shown in Table 1. In addition to the usual drugs, 23 patients received an unclassified anti-anginal: molsidomine $(\mathrm{n}=5)$, nicorandil $(\mathrm{n}=9)$, or trimetazidine $(n=9)$, and 6 patients were treated with a central antihypertensive medication. The mean number of antithrombotic and anti-anginal medications was 1.2 and 1.9 per patient, respectively.

\section{Ejection Fraction}

Preoperative ejection fraction was measured by echocardiography or ventriculography according to the Simpson equation, whereas late ejection fraction was obtained by echocardiography at the termination of follow-up. All values within the normal range were allocated $65 \%$.

\section{Control Angiograms}

Controls were achieved by conventional angiography in 79 patients and computed tomography (CT) in 123 patients. Among them, 47 patients $(23 \%)$ had undergone a previous control angiogram, the result of which was not incorporated in this study. For each method, the patient clinical status at the time of control angiogram is shown in Table 2.

Conventional angiography was performed by retrograde femoral artery catheterization under standard fluoroscopy using an iodine contrast agent. CT examination was performed with a 64-slice CT scanner after injection of an intravenous bolus of $120 \mathrm{~mL}$ nonionic iodine contrast agent (iomeprol 400). If a patient's heart rate exceeded 85 beats $/ \mathrm{min}$, a slow infusion of intravenous atenolol $(10 \mathrm{mg})$ was administered before the examination. Oral antidiabetic medications were discontinued for 6 hours before the examination. Transaxial slices were recorded with retrospective electrocardiogram (ECG) gating, and images were reconstructed with maximum-intensity projection, curved multiplanar reformation, cross-sectional imaging, and volume rendering.

\section{Coronary Grafts}

There were 2.57 grafts per patient, and 520 grafts were angiographically controlled. There were 230 radial artery conduits, with 28 patients having received 2 radial artery grafts. The radial artery was proximally anastomosed to the ascending aorta in 224 cases and to the left internal thoracic artery (ITA) in 6 cases. A sequential radial artery graft had been constructed in 23 cases (right coronary, $\mathrm{n}=2$; diagonal or circumflex territories, $\mathrm{n}=$ 21). A total of 190 left ITA grafts were controlled, including 187 pedicled and 3 free grafts. The left ITA was sequentially anastomosed in 7 cases (diagonal-left anterior descending [LAD], $\mathrm{n}=6$; diagonal-circumflex, $\mathrm{n}=1$ ). There were 30 right ITA conduits, of which 18 were pedicled and 12 were free grafts, all with only 1 anastomosis. Seventy saphenous vein grafts were controlled, including 4 sequential grafts (right coronary, $\mathrm{n}=2$; diagonal or circumflex territories, $\mathrm{n}=2$ ). The target coronaries are shown in Figure E1 for each graft category. In case of sequential bypass, only the most distal target artery was considered. The radial artery was anastomosed to the following coronary arteries: LAD, 2 (1\%); circumflex, 138 (58\%); diagonal, 38
TABLE 1. Patient clinical characteristics

\begin{tabular}{lr}
\hline \multicolumn{1}{c}{ Risk factors } & N (\%) \\
\hline Systemic hypertension & $120(59 \%)$ \\
Dyslipidemia & $179(89 \%)$ \\
Diabetes & $71(35 \%)$ \\
Smoking & $117(58 \%)$ \\
Multifocal atheroma & \\
Carotid disease & $25(12 \%)$ \\
Aortoiliac/peripheral artery disease & $43(21 \%)$ \\
Antithrombotic therapy & \\
Aspirin & $145(72 \%)$ \\
Clopidogrel & $63(31 \%)$ \\
Anticoagulant & $32(16 \%)$ \\
Anti-anginal treatment & \\
Nitrates & $31(15 \%)$ \\
Beta-blockers & $145(72 \%)$ \\
Calcium channel blockers & $90(45 \%)$ \\
ACE inhibitors/angiotensin antagonists & $100(49 \%)$ \\
Unclassified coronary vasodilator & $23(11 \%)$ \\
Central antihypertensive therapy & $6(3 \%)$ \\
\hline
\end{tabular}

$A C E$, Angiotensin-converting enzyme.

(16\%); and right coronary, $56(25 \%)$. The left ITA was anastomosed to the following coronary arteries: LAD, 181 (95\%); diagonal, 4 (2\%); and circumflex, $5(3 \%)$. The right ITA was anastomosed to the following coronary arteries: LAD, 5 (17\%); diagonal, 4 (13\%); circumflex, 6 (20\%); right coronary, $15(50 \%)$. The venous grafts were anastomosed to the following coronary arteries: diagonal, 17 (24\%); circumflex, 17 (24\%); and right coronary, $36(52 \%)$.

\section{Statistical Analysis}

Descriptive data for continuous variables are presented as means with standard deviation. Patient groups were compared by chi-square test for categoric values and the Student $t$ test for continuous variables.

\section{RESULTS}

\section{Ejection Fraction}

The mean ejection fraction at the end of follow-up was $54 \% \pm 11 \%$ and was less than $40 \%$ in 12 patients. It was significantly lower than the preoperative ejection fraction $(57 \% \pm 9 \%, P=.0088)$.

\section{Percutaneous Intervention}

Forty-eight patients $(24 \%)$ underwent at least 1 percutaneous intervention throughout the follow-up period.

TABLE 2. Indications for angiography

\begin{tabular}{lccc}
\hline \multicolumn{1}{c}{ Clinical status } & $\begin{array}{c}\text { Conventional } \\
\text { angiogram } \\
\mathbf{N = 7 9}\end{array}$ & $\begin{array}{c}\text { CT } \\
\text { angiography } \\
\mathbf{N = 1 2 3}\end{array}$ & $\begin{array}{c}\text { Total } \\
\mathbf{N = 2 0 2}\end{array}$ \\
\hline Acute myocardial infarction & $4(5 \%)$ & 0 & $4(2 \%)$ \\
Angina pectoris & $36(46 \%)$ & $10(8 \%)$ & $46(23 \%)$ \\
Congestive heart failure & $7(8.5 \%)$ & $6(5 \%)$ & $13(6 \%)$ \\
Positive stress test/scintigraphic & $8(10 \%)$ & $4(3 \%)$ & $12(6 \%)$ \\
$\quad$ abnormalities & & & \\
Calcified aortic valve stenosis & $6(7.5 \%)$ & 0 & $6(3 \%)$ \\
Asymptomatic (routine control) & $18(23 \%)$ & $103(84 \%)$ & $121(60 \%)$ \\
\hline
\end{tabular}

$C T$, Computed tomography. 

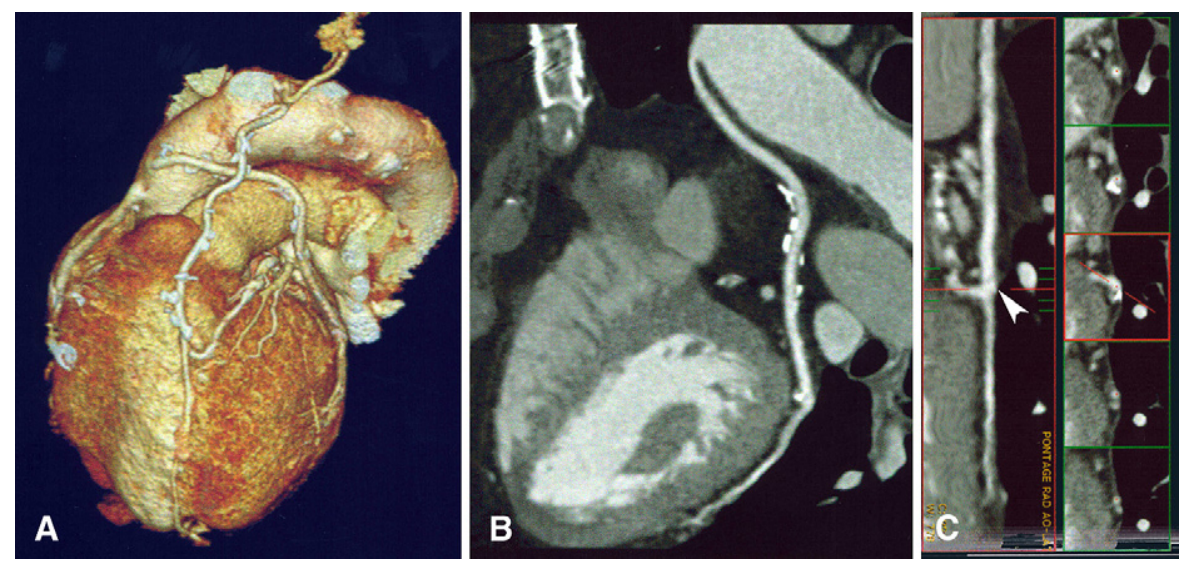

FIGURE 1. CT angiography scan at 9 years. A, Volume rendering showing a radial artery-to-obtuse marginal conduit with a left ITA to LAD graft. B, Maximum-intensity projection with curved multiplanar reformatted image of the radial artery conduit. C, Cross-sectional imaging demonstrating full graft patency. Open anastomosis (arrow) to the target.

Percutaneous interventions resulting from the findings of the most recent angiogram and performed during the same hospitalization stay were also included. Myocardial ischemia was the indication for percutaneous coronary intervention (PCI) in all cases: acute infarction $(\mathrm{n}=3)$, angina $(\mathrm{n}=33)$, or ECG stress test or scintigraphic abnormalities $(\mathrm{n}=12)$. The mean time interval between surgery and percutaneous intervention was $7.6 \pm 4.5$ years $(0.2-16.7$ years postoperatively). In total, 55 PCIs were performed as 1 single PCI (42 patients), 2 PCIs (5 patients), and 3 PCIs (1 patient). The indication for PCI was graft failure in 38 patients (radial, $\mathrm{n}=24$; ITA, $\mathrm{n}=10$; and vein, $\mathrm{n}=4$ ) and incomplete revascularization or progression of coronary disease in 17 patients. Sixty-seven vessels were dilated with balloon alone $(\mathrm{n}=12)$ and stenting $(\mathrm{n}=55)$. The site of percutaneous dilation was graft stenosis in 19 patients, coronary stenosis proximal to an occluded graft in 35 patients, and coronary stenosis distal to a patent graft or on a nongrafted vessel in 13 patients. Direct PCI of a conduit was performed in 13 radial arteries (Figure E2) (5.6\% of controlled radial arteries), 4 ITAs ( $1.8 \%$ of all controlled ITAs), and 2 veins ( $2.8 \%$ of controlled veins). PCI of a native coronary artery was achieved in 48 patients: left main $(n=7), \operatorname{LAD}(n=8)$, diagonal $(n=3)$, circumflex $(n=16)$, and right coronary $(\mathrm{n}=14)$.

\section{Reoperation}

Cardiac reoperation was required in 9 patients $(4.4 \%)$ after a mean period of $10.5 \pm 2.9$ years (6.1-16.9 years). These included reoperations performed immediately after the most recent angiogram, which was part of the preoperative investigation. In 8 patients, the indication for reoperation was valve dysfunction. Six aortic and 2 mitral valve replacements were performed, including associated coronary bypass grafting in 2 patients. One patient underwent
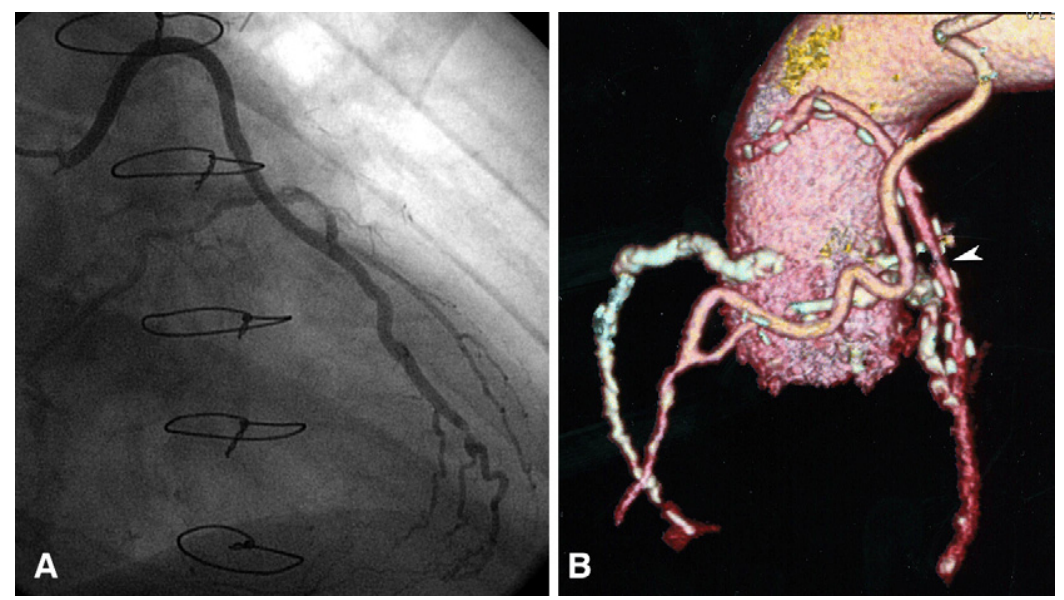

FIGURE 2. Radial artery-to-diagonal controlled by conventional angiogram at 11 years (A) and CT at 13 years (B) (volume rendering). 

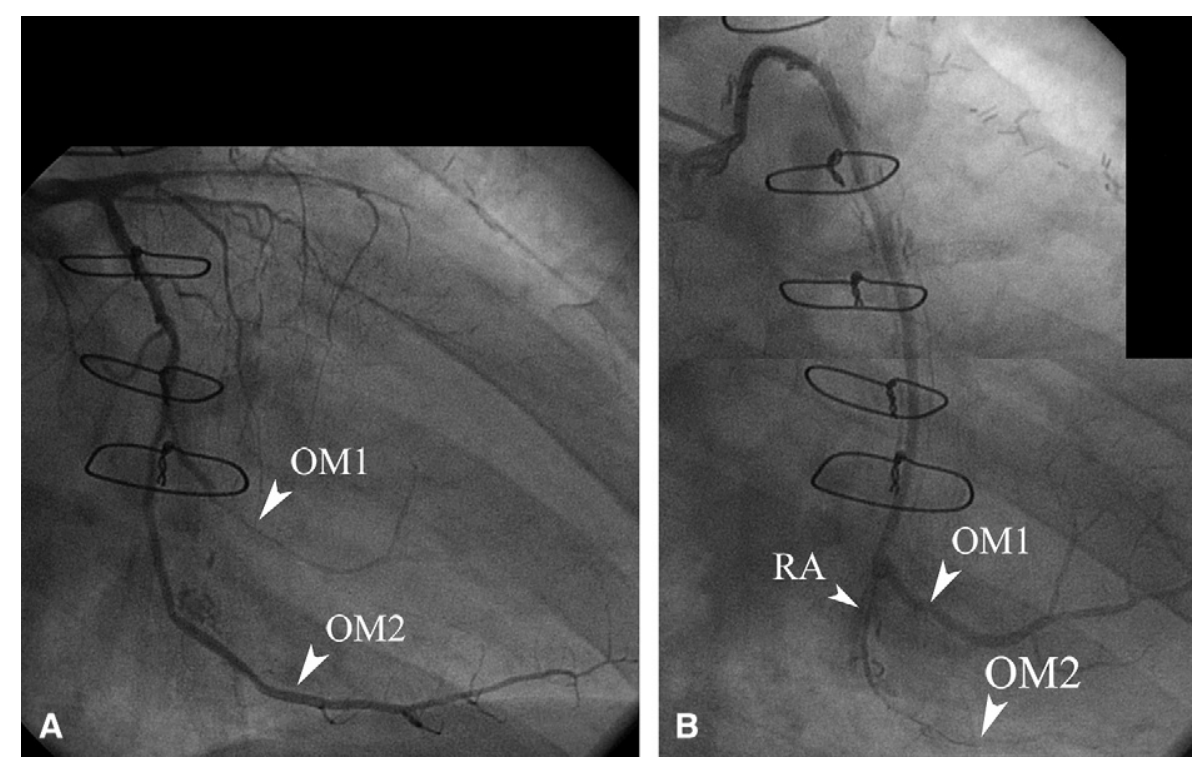

FIGURE 3. Competitive flow resulting in string-like involution of the distal segment of a radial artery graft sequentially anastomosed to the first and second obtuse marginal at 8 years: A, Circumflex coronary artery free from significant stenosis providing unrestricted flow to the second obtuse marginal, whereas the first obtuse marginal is hardly visible. B, Radial artery supplying the first obtuse marginal with string-like involution of its distal segment and no opacification of the second obtuse marginal. $R A$, Radial artery; $O M$, obtuse marginal.

reoperation for recurrence of angina $(0.5 \%)$ related to intrastent stenosis of a left ITA to LAD graft, and a single offpump bypass was performed.

\section{Graft Patency}

The time interval between surgery and control was shorter when conventional angiography was used compared with CT angiography $(9.1 \pm 3.2$ years vs $10.8 \pm 3.3$ years, respectively; $P<.001)$. CT allowed a reliable evaluation of graft patency in all cases for a radiation exposure of $1655 \pm 531$ mGray.cm. Among radial artery grafts, 192 $(83 \%)$ were patent (Figure E3; Figures 1-4) and $38(17 \%)$ were occluded or presented a diffuse string-like narrowing. The clinical status of patients with an occluded radial artery graft $(\mathrm{n}=37)$ was as follows: acute infarction due to radial artery graft thrombosis $(n=2)$, angina $(n=13)$, congestive heart failure $(n=1)$, positive ECG stress test or scintigraphic abnormalities $(n=4)$, and lack of symptom $(n=17)$, of which 9 patients had a negative ECG stress test or normal scintigraphy. Retrospective analysis of the preoperative angiogram allowed identifying a factor that could have promoted graft failure in 24 patients $(63 \%)$. A situation of competitive flow was observed in 16 patients: low-grade $(<60 \%)$ stenosis on the target artery $(n=10)$ (Figure 3$)$ or proximal left main stenosis with patent left ITA to LAD $(n=6)$, of whom 5 had widely open stents. The radial artery graft had been anastomosed to a chronically occluded coronary artery in 8 other patients. No obvious determinant of radial artery graft failure was found in 14 patients. The patency of radial artery grafts was lower than that of left ITA grafts: 181 patent and 8 occluded grafts for a $95 \%$ patency $(P<.001)$. The patency was similar to that of right ITAs: 26 patent and 4 occluded
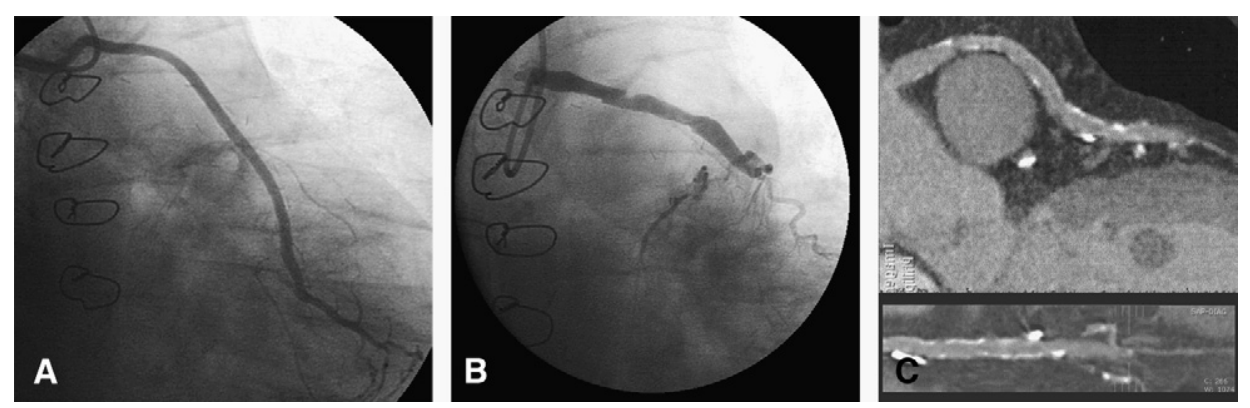

FIGURE 4. A, Radial artery to obtuse marginal at 16 years. B, Same patient: severe atheromatous graft disease resulting in moderate stenosis of a saphenous vein conduit. In this patient, an additional vein graft was occluded. C, Other patient controlled at 16 years: CT scan demonstrating extensive calcification of the vein graft wall. In this case, the radial artery graft was occluded. 
grafts for an $87 \%$ patency $(P=.66$ vs radial artery and $P=.06$ vs left ITA). The patency was also similar to that of vein grafts: 56 patent and 14 occluded grafts for an $81 \%$ patency $(P=.50 \mathrm{vs}$ radial artery and $P<.001 \mathrm{vs}$ left ITA).

Acute myocardial infarction was caused by left ITA-toLAD distal anastomosis thrombosis in 1 patient and abrupt occlusion of a native coronary artery in 1 patient. Patients with symptoms or positive ECG stress test/scintigraphic abnormalities had lower although statistically insignificant radial artery graft patency than asymptomatic patients: 117 of $136(80 \%)$ versus 75 of $94(86 \%)$, respectively $(P=.21)$. When considering all grafts $(\mathrm{n}=520)$, the difference became significant with 274 of $303(83 \%)$ versus 181 of $217(90 \%)$ patent grafts, respectively $(P<.02)$. Antithrombotic medication and anti-anginal therapy did not individually influence radial artery graft patency in a consistent manner (Table E1). The site of the target artery markedly affected all-graft patency, with the highest patency observed in the LAD territory ( $180 / 188$ or $96 \% P<.001$ vs right coronary and vs circumflex, $P=.02$ vs diagonal) and the lowest patency observed in the circumflex area $(130 / 162$ or $80 \% P=.21$ vs diagonal and $P=.42$ vs right coronary). The patencies of grafts constructed on the diagonal and the right coronary artery were 55 of $63(87 \%)$ and 90 of $107(84 \%)$, respectively. The patency of LAD grafts was higher than that of non-LAD grafts $(275 / 332$ or $82 \% ; P<.001)$ (Table E1). Three stenoses of a subclavian artery giving rise to an ITA graft and 1 lung tumor were revealed by the CT control.

\section{DISCUSSION}

The aim of the present study was to focus on the late patency of radial artery grafts used for coronary bypass grafting, and the methodology was adapted accordingly. In previous studies in which both clinical and angiographic results were analyzed, ${ }^{2,3}$ a series of consecutive patients were reviewed and all of them had been proposed a control coronary angiogram. The studies were discontinued whenever 50 consecutive angiograms had been performed. ${ }^{2,3}$ In the present study, because of the long follow-up, we chose first to collect all data available in patients who underwent operation in a well-defined time period (1989-2001). All angiographic results obtained beyond 5 years postoperatively were included in the study. The date of the most recent control angiogram marked the end of the follow-up period. Late survival was not considered as a parameter because by definition all patients were alive at the termination of the study. This research carried out over such a long observation period (up to 20 years) was made difficult by the advanced age of many patients (up to 89 years) and the frequent comorbidities; thus, a conventional angiography could not be systematically considered. The majority of conventional angiograms in the study were motivated by the presence of cardiac symptoms or suspicion of myocardial ischemia on ECG stress test or scintigraphy. The technologic advances of CT imaging enable opacification of coronary grafts to be viewed with an excellent resolution ${ }^{4,5}$ (Figures 1 and 2). This noninvasive method was widely applied in this study, and angiographic controls were obtained by a 64-slice CT scanner in most of the patients who were asymptomatic. In our experience the only contraindication was severe renal insufficiency (creatinine level $>200 \mu \mathrm{mol} / \mathrm{L}$ ). In case of moderate renal insufficiency, large-volume infusion was maintained before and during the examination. Atrial fibrillation did not cause significant difficulty because a large number of patients $(72 \%)$ were prescribed beta-blockers, and in case of an excessively fast heart rate an intravenous infusion of atenolol was instituted before the image acquisition. Artifacts were occasionally observed in patients with difficulty in breathholding that could require repeating the acquisition process or with reflection generated by the numerous metallic clips that had been used for obliterating radial artery collaterals in the early phase of our experience. However, it has invariably been possible to ascertain graft patency. In case of a long-lasting ischemic heart disease, the native coronary arteries were usually the site of severe calcifications that often precluded their reliable assessment by $\mathrm{CT}$; however, arterial grafts and, in particular, the radial artery conduit remained totally free of calcification, and remarkably sharp images were obtained by a 64-slice CT scanner (Figures 1 and 2). In rare cases, the quantification of a suspected graft stenosis or the distinction between string sign and occlusion has caused some difficulty. This method was recently introduced into the armamentarium of patient follow-up, and most examinations have been performed within the past 2 years; consequently, follow-up was more prolonged than in patients controlled by conventional angiography.

In this study the radial artery graft patency rate was $83 \%$ after a mean follow-up of 10 years. This observation corroborated the 10 -year study by Possati and colleagues ${ }^{6}$ and previous long-term patency studies by other groups at 5 years. ${ }^{7-9}$ Late CT scan controls in our study confirmed a complete absence of radial artery wall calcification during the 20-year period of observation (Figure 2) as opposed to what is commonly observed with venous conduits (Figure 4).

In case of radial artery graft failure, the retrospective analysis of preoperative angiograms frequently allowed the identification of a promoting factor. Thrombosis and string-like involution were the consequences of a poor graft flow, which in this study was often related to a competitive flow situation as previously reported. ${ }^{10-14}$ In some cases, the radial graft had been inserted on a target artery presenting with a low degree of stenosis and no hemodynamic restriction or in which stenting had remained widely open. Otherwise, the bypass graft had been constructed beyond a proximal left main stenosis, sparing the bifurcation and allowing backflow from the left ITA-to-LAD graft toward the target circumflex network. Conversely, in other cases the radial graft had been anastomosed to a chronically 
occluded target coronary artery. Because of elevated resistance related to more or less pronounced fibrotic transformation of the myocardium together with well-developed collateral coronary circulation, a low-flow state ensued that prompted graft closure. In some cases, however, there was no obvious factor contributing to graft occlusion. Of note, two thirds of patients have remained clinically asymptomatic despite an occluded radial artery graft, and when an ECG stress test or scintigraphy was performed, they frequently failed to demonstrate any myocardial ischemia.

According to the statistical analysis in this study, no pharmacologic therapy individually appeared as a determinant of radial artery graft patency (Table E1). Although this is common clinical practice, previous reports have also failed to demonstrate any benefit of using chronic antispastic drug therapy, such as calcium channel blockers, in patients who have undergone radial artery grafting. ${ }^{3,14,15}$ It should still be emphasized that most patients were receiving antithrombotic therapy and 1 or 2 classes of anti-anginal medications. Because of possible interactions between medications, it seems difficult to conclude that any of these drugs had no effect on radial graft patency.

The merits of the radial artery conduit compared with the ITA graft or the saphenous vein are still a matter of debate. ${ }^{9,16}$ Some studies have attempted to show differences among the various types of conduits on the basis of clinical parameters, such as survival or freedom from ischemic events. ${ }^{17-20}$ Because of the multiplicity of confounding parameters, even sophisticated statistical tests on large cohorts of patients have failed to identify the type of graft as a determinant of clinical outcome. ${ }^{18,19}$ Methodological biases are frequent, as illustrated by the contradictory findings of these reports. ${ }^{17-20}$ Angiography is the ultimate test to reliably evaluate graft performance. Although the method is discriminating, the interpretation of angiographic data must take into consideration all factors influencing graft patency, of which some may be more determinant than the type of conduit. In the present study, the 10-year patency of radial artery grafts was lower than that of left ITA grafts and seemed similar to those of right ITAs and vein grafts. Nevertheless, the site of the target artery is a well-known and powerful parameter influencing coronary graft patency. ${ }^{9-11}$ In this study, the revascularized areas varied tremendously according to the type of conduit (Figure E1). The radial artery grafts shared the myocardial territories of lesser extent with the right ITAs and the vein grafts. In contrast, a majority of left ITAs were anastomosed to the LAD, whose large run-off including the septal branches would guarantee a high graft flow. In this study and others, ${ }^{9-11}$ the patency of LAD grafts was significantly higher than that of nonLAD grafts irrespective of the type of conduit (Table E1). Thus, the benefit offered by the left ITA seemed indiscernible from the advantage provided by the large extent of the LAD territory.
The 10-year patency rate of vein grafts in this study was $81 \%$, surprisingly higher than the usually reported values in the literature. ${ }^{21}$ Some explanations can be proposed: 1 ) The total number of grafts was adjusted to meet the need for a complete revascularization of the main coronary trunks (2.57 grafts/patient). No attempt was made to graft the thinnest and most distal branches, which would have led to multiply the venous conduits inserted on small-caliber arteries. ${ }^{21}$ 2) Because arterial conduits were favored ( $87 \%$ of arterial grafts), only short saphenous segments harvested at the leg and with faultless quality were used, knowing that large-diameter veins harvested at the thigh or varicose veins are more prone to failure. ${ }^{21}$ Nevertheless, signs of saphenous graft disease have occasionally been noted on late angiograms in this series (Figure 4).

If one considers all grafts, patency was lower in patients presenting with cardiac symptoms, positive ECG stress, or scintigraphic abnormalities than in totally asymptomatic patients, which is consistent with previous studies. ${ }^{22,23}$ In case of acute myocardial infarction, thrombosis of an arterial graft was detected in 3 patients (radial artery graft in 2 patients and ITA graft in 1 patient) and occlusion of a native coronary artery in 1 patient.

An important limitation of the present study concerning the analysis of the determinants of radial artery graft patency should be acknowledged. Indeed, less than one third of the total cohort who received a radial artery graft underwent a late ( $>5$ years) angiogram. Thus, a larger number of angiographic studies, including early control and iterative angiograms, in the same patient might have strengthened the statistical power and allowed further clarification of the determinants of radial graft patency.

The rate of late coronary reoperation was low in this series $(0.5 \%$ at 10 years), and most reinterventions were meant to address valve dysfunction (3.9\%), which was most often a calcified aortic stenosis. The low coronary reoperation rate could lawfully be imputed to the quality of the surgical revascularization, as illustrated by the high graft patency at 10 years. However, the progress in PCI techniques should not be underestimated. By the end of follow-up, 1 of 4 patients had benefited from 1 or more PCIs; otherwise reoperation might occasionally have been necessary. The sites of PCIs were most often a native coronary artery proximal to a patent graft (protected left main trunk, proximal LAD), on the target artery of an occluded graft, or on a nongrafted artery. In a few cases, PCI directly involved a bypass graft (venous or arterial). The significance of radial artery graft stenosis and its treatment by PCI (Figure E2) has been discussed in a separate publication. ${ }^{24}$ Throughout the study period, stenting progressively superseded balloon dilatation alone. Because of the methodology, the present study overestimated the need for reoperation or PCI late after radial artery grafting. An angiogram was performed before these 2 procedures; therefore, all reoperations and PCIs beyond 5 years have supposedly 
been included in the study. By extrapolating the total number of coronary bypasses with radial artery grafts during the study period, the predicted incidence of reoperation would be $1.5 \%$ (including coronary reoperation: $0.16 \%$ ) and the need for PCI would be $7.7 \%$ at 5 to 20 years postoperatively.

\section{CONCLUSIONS}

The radial artery as a coronary graft has shown excellent angiographic results in the long term and has remained almost free from graft disease. The main determinants of graft failure are related to the degree of stenosis and the site of the target vessel. Multislice CT angiography allowed noninvasive and reliable graft visualization and provided information for patient follow-up. Together with the efficacy of surgical revascularization by arterial grafting, the progress in PCI has considerably reduced the need for late coronary reoperations. The use of the radial artery as a second graft to complement the left ITA is a valuable option that provides high quality and durable angiographic results.

\section{References}

1. Carpentier A, Guermonprez JL, Deloche A, Frechette C, Dubost C. The aorta-tocoronary radial bypass graft: a technique avoiding pathological changes in grafts. Ann Thorac Surg. 1973;16:111-21.

2. Acar C, Jebara VA, Portoghese M, Beyssen B, Pagny JY, Grare P, et al. Revival of the radial artery for coronary artery bypass grafting. Ann Thorac Surg. 1992;54: 652-60.

3. Acar C, Ramsheyi A, Pagny JY, Jebara V, Barrier P, Fabiani JN, et al. The radial artery for coronary artery bypass grafting: clinical and angiographic results at five years. J Thorac Cardiovasc Surg. 1998;116:981-9.

4. Ropers D, Pohle FK, Kuettner A, Pflederer T, Anders K, Daniel WG, et al. Diagnostic accuracy of noninvasive coronary angiography in patients after bypass surgery using 64-slice spiral computed tomography with 330-ms gantry rotation. Circulation. 2006;114:2334-41.

5. Feuchtner GM, Schachner T, Bonatti J, Friedrich GJ, Soegner P, Klauser A, et al. Diagnostic performance of 64-slice computed tomography in evaluation of coronary artery bypass grafts. Am J Roentgenol. 2007;189:574-80.

6. Possati G, Gaudino M, Prati F, Alessandrini F, Trani C, Glieca F, et al. Long-term results of the radial artery used for myocardial revascularization. Circulation. 2003;108:1350-4

7. Cameron J, Trivedi S, Stafford G, Bett JH. Five-year angiographic patency of radial artery bypass grafts. Circulation. 2004;110:II23-6.

8. Hayward PA, Buxton BF. Contemporary coronary graft patency: 5-year observational data from a randomized trial of conduits. Ann Thorac Surg. 2007;84: 795-9.
9. Collins P, Webb CM, Chong CF, Moat NE. Radial Artery Versus Saphenous Vein Patency (RSVP) Trial Investigators. Radial artery versus saphenous vein patency randomized trial: five-year angiographic follow-up. Circulation. 2008;117: 2859-64.

10. Maniar HS, Sundt TM, Barner HB, Prasad SM, Peterson L, Absi T, et al. Effect of target stenosis and location on radial artery graft patency. $J$ Thorac Cardiovasc Surg. 2002;123:45-52.

11. Gaudino M, Alessandrini F, Pragliola C, Cellini C, Glieca F, Luciani N, et al. Effect of target artery location and severity of stenosis on mid-term patency of aorta-anastomosed vs. internal thoracic artery-anastomosed radial artery grafts. Eur J Cardiothorac Surg. 2004;25:424-8.

12. Desai ND, Naylor CD, Kiss A, Cohen EA, Feder-Elituv R, Miwa S, et al. Radial Artery Patency Study Investigators. Impact of patient and target-vessel characteristics on arterial and venous bypass graft patency: insight from a randomized trial Circulation. 2007;115:684-91.

13. Yie K, Na CY, Oh SS, Kim JH, Shinn SH, Seo HJ. Angiographic results of the radial artery graft patency according to the degree of native coronary stenosis. Eur J Cardiothorac Surg. 2008;33:341-8.

14. Gaudino M, Luciani N, Nasso G, Salica A, Canosa C, Possati G. Is postoperative calcium channel blocker therapy needed in patients with radial artery grafts? J Thorac Cardiovasc Surg. 2005;129:532-5.

15. Patel A, Asopa S, Dunning J. Should patients receiving a radial artery conduit have post-operative calcium channel blockers? Interact Cardiovasc Thorac Surg. 2006;5:251-7.

16. Desai ND, Cohen EA, Naylor CD, Fremes SE. Radial Artery Patency Study Investigators. A randomized comparison of radial-artery and saphenous-vein coronary bypass grafts. $N$ Engl J Med. 2004;351:2302-9.

17. Zacharias A, Habib RH, Schwann TA, Riordan CJ, Durham SJ, Shah A. Improved survival with radial artery versus vein conduits in coronary bypass surgery with left internal thoracic artery to left anterior descending artery grafting. Circulation. 2004;109:1489-96

18. Hayward PA, Hare DL, Gordon I, Matalanis G, Buxton BF. Which arterial conduit? Radial artery versus free right internal thoracic artery: six-year clinical results of a randomized controlled trial. Ann Thorac Surg. 2007;84:493-7.

19. Hayward PA, Hare DL, Gordon I, Buxton BF. Effect of radial artery or saphenous vein conduit for the second graft on 6-year clinical outcome after coronary artery bypass grafting. Results of a randomised trial. Eur J Cardiothorac Surg. 2008;34:113-7.

20. Zacharias A, Schwann TA, Riordan CJ, Durham SJ, Shah AS, Habib RH. Late results of conventional versus all-arterial revascularization based on internal thoracic and radial artery grafting. Ann Thorac Surg. 2009;87:19-26.

21. Shah PJ, Gordon I, Fuller J, Seevanayagam S, Rosalion A, Tatoulis J, et al. Factors affecting saphenous vein graft patency: clinical and angiographic study in 1402 symptomatic patients operated on between 1977 and 1999. J Thorac Cardiovasc Surg. 2003;126:1972-7.

22. Shah PJ, Seevanayagam S, Rosalion A, Gordon I, Fuller J, Raman JS, et al Patency of the radial artery graft: angiographic study in 209 symptomatic patients operated between 1995 and 2002 and review of the current literature. Heart Lung Circ. 2004;13:379-83.

23. Buxton BF, Durairaj M, Hare DL, Gordon I, Moten S, Orford V, et al. Do angiographic results from symptom-directed studies reflect true graft patency? Ann Thorac Surg. 2005;80:896-900.

24. Goube P, Hammoudi N, Pagny JY, Boutekadjirt R, Toledano D, Achouh P, et al Radial artery graft stenosis treated by percutaneous intervention. Eur J Cardiothorac Surg. 2009 Aug 21 [Epub ahead of print]. 


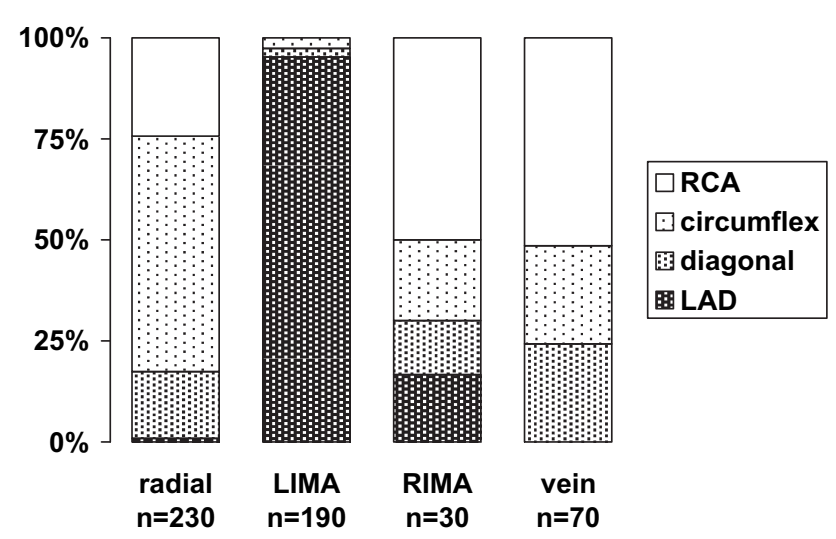

FIGURE E1. Implantation sites of coronary grafts. $R C A$, Right coronary artery; $L A D$, left anterior descending; LITA, left internal thoracic artery; RITA, right internal thoracic artery.
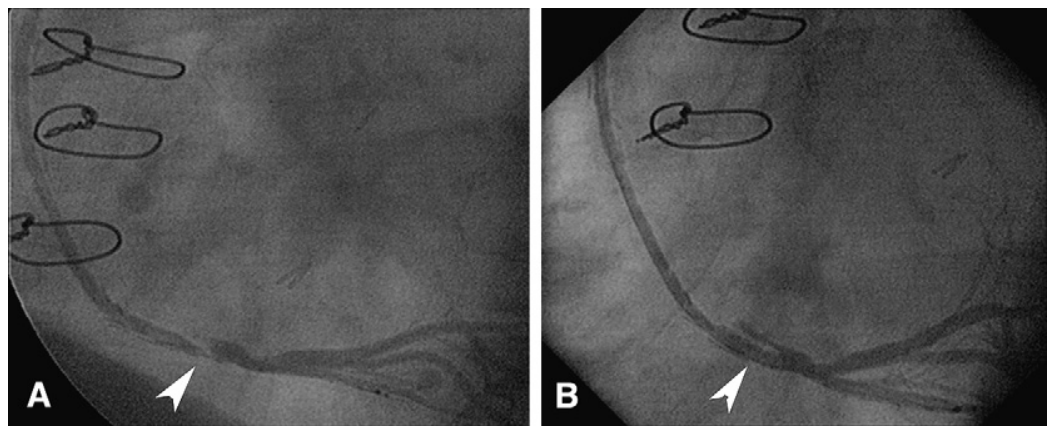

FIGURE E2. A, Stenosis (arrow) of the distal anastomosis of a radial artery graft to right coronary artery at 6 years. B, Result after stent implantation (arrow). 

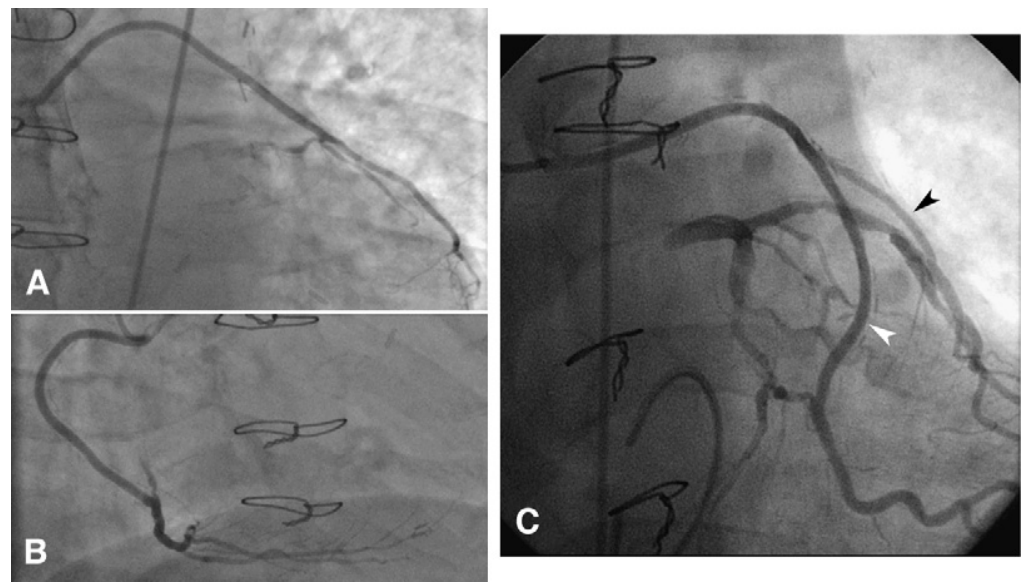

FIGURE E3. A, B, Radial artery grafts to diagonal and right coronary artery at 9 years in the same patient. C, Two radial artery grafts at 10 years: radial artery-to-diagonal branch (black arrow) proximally anastomosed to the aorto-to-obtuse marginal graft (white arrow).

TABLE E1. Determinants of radial artery graft and all-graft patency

\begin{tabular}{|c|c|c|c|}
\hline & \multicolumn{2}{|c|}{ RA graft patency } & \multirow[b]{2}{*}{$P$} \\
\hline & Yes & No & \\
\hline $\begin{array}{l}\text { Symptoms or positive ECG } \\
\text { stress test/scintigraphy }\end{array}$ & $117 / 136(80 \%)$ & $75 / 94(86 \%)$ & .21 \\
\hline \multicolumn{4}{|l|}{ Antithrombotic therapy } \\
\hline Aspirin & $139 / 162(86 \%)$ & $51 / 61(80 \%)$ & .26 \\
\hline Clopidogrel & $54 / 69(78 \%)$ & $136 / 157(87 \%)$ & .11 \\
\hline Anticoagulant & $26 / 34(76 \%)$ & $164 / 192(85 \%)$ & .19 \\
\hline \multicolumn{4}{|l|}{ Anti-anginal } \\
\hline Nitrates & $31 / 37(84 \%)$ & $159 / 189(84 \%)$ & .96 \\
\hline Beta-blockers & $141 / 163(87 \%)$ & $49 / 63(78 \%)$ & .11 \\
\hline Calcium channel blockers & $80 / 98(82 \%)$ & $110 / 128(86 \%)$ & .38 \\
\hline \multirow{3}{*}{$\begin{array}{l}\text { ACE inhibitors/angiotensin } \\
\text { antagonists }\end{array}$} & $95 / 111(86 \%)$ & $95 / 115(83 \%)$ & .54 \\
\hline & \multicolumn{2}{|c|}{ All-graft patency } & \\
\hline & Yes & No & $P$ \\
\hline $\begin{array}{l}\text { Symptoms or positive ECG } \\
\text { stress test/scintigraphy }\end{array}$ & $274 / 303(83 \%)$ & $181 / 217(90 \%)$ & $<.02$ \\
\hline LAD as target artery & $180 / 188(96 \%)$ & $275 / 332(82 \%)$ & $<.001$ \\
\hline
\end{tabular}

$R A$, Radial artery; $E C G$, electrocardiogram; $A C E$, angiotensin-converting enzyme; $L A D$, left anterior descending. 